\title{
Design and Implementation of a Three-Phase Active T-Type NPC Inverter for Low-Voltage Microgrids
}

\author{
Rick Chen ${ }^{1}$, Ying-Yu Tzou ${ }^{2}$ \\ ${ }^{1}$ AcBel Polytech Inc., Taiwan \\ ${ }^{2}$ Institute of Electrical Control Engineering, National Chiao Tung University, Taiwan \\ Email:yytzou@mail.nctu.edu.tw
}

How to cite this paper: Chen, R. and Tzou, Y.-Y. (2017) Design and Implementation of a Three-Phase Active T-Type NPC Inverter for Low-Voltage Microgrids. Energy and Power Engineering, 9, 70-77. https://doi.org/10.4236/epe.2017.94B009

Received: February 13, 2017

Accepted: March 30, 2017

Published: April 6, 2017

\begin{abstract}
This paper presents the design and implementation of a $3 \mathrm{kVA}$ three-phase active T-type neutral-point clamped (NPC) inverter with GaN power devices for low-voltage microgrids. The designed inverter is used in a battery-based energy system (BESS) for power conversion optimization in applications to low-voltage microgrids. A modular design method has been developed for the design and implementation of the AT-NPC inverter. Experimental verification has been carried out based on a 3-kW three-phase T-Type NPC gridconnected inverter. FPGA based digital control technique has been developed for the current control of the three-level three-phase grid inverter. A maximum efficiency of $98.49 \%$ has been achieved within a load range from $50 \%$ to $75 \%$.
\end{abstract}

\section{Keywords}

Active T-Type NPC Inverter, Modular Design Methodology, Loss Analysis, Efficiency Optimization

\section{Introduction}

Multi-level converters (MLC) have been traditionally adopted for static power conversion and motor drives in medium voltage applications [1] [2]. Although various converter topologies have been developed for medium voltage applications, the three-level neutral-point clamped (NPC) converter topology is the most frequently selected for industrial applications due to its advantages of simplicity and reliability [3] [4] [5]. With the advances of modularized power devices developed for the implementation of active T-type NPC inverters [6] [7] [8] [9], AT-NPC inverters are becoming a competitive choice for PV inverters and 
motor drives in low voltage applications [10]-[15].

\section{T-Type NPC Inverter}

The 3-level active T-type NPC inverter, as show in Figure 1(b), provides an additional middle point of its DC-link voltage for its voltage switching, and thus the inverter voltage is reduced to half compared with the conventional 2-level inverter as shown in Figure 1(a). The reduction of voltage switching level provides advantages such as lower switching losses, smaller filters for both the dc-link capacitor and output filters, lower EMI and leakage current, higher power density with improved efficiency.

The drawbacks of the AT-NPC inverters are extra AC switches with their corresponding isolated gate drives are required, more sophisticated PWM strategy and balancing control scheme are required. However, with the development of new generation wide bandgap (WBG) semiconductors such as Gallium Nitride $(\mathrm{GaN})$ and Silicon Carbide ( $\mathrm{SiC}$ ), and the high-performance advanced FPGA embedded microprocessors, an active T-type inverter phase leg may become a standard power module for the implementation of an idea renewable power conversion system.

Vertical GaN devices provide advantages such as high voltage blocking capability, very low conduction resistance with very small footprint, and high operating temperature, but still exists a major challenge for reliable mass production.

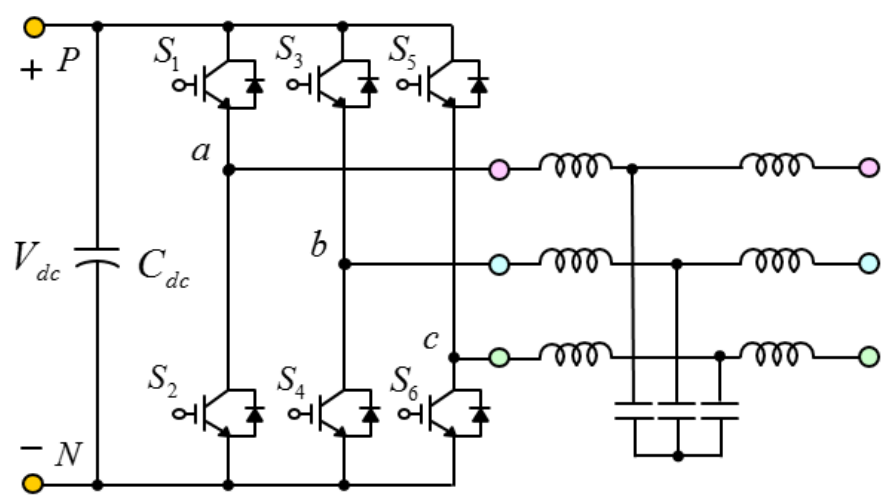

(a)

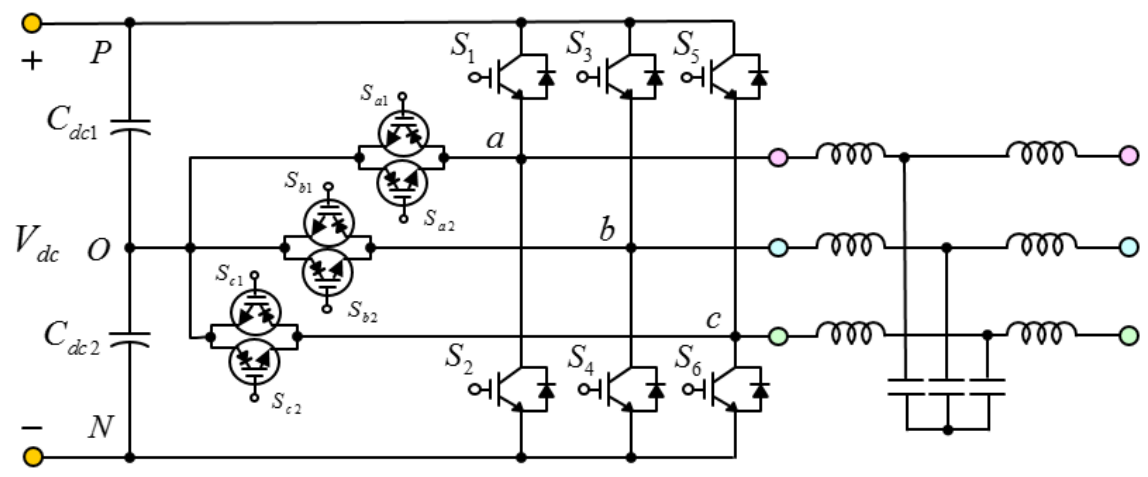

(b)

Figure 1. Schematics of (a) 2-L and (b) 3-L active T-type NPC inverters. 
On the other hand, lateral GaN-on-Si devices are a promising alternative. A High-electron-mobility transistor (HEMT), also known as heterostructure FET (HFET), is a field-effect transistor incorporating a junction between two materials with different band gaps. GaN HEMT power devices can achieve low onstate resistance and high-speed switching performance, and provides a possibility to miniaturize the connected power filter components with sophisticated digital control techniques [16]-[21].

\section{Implementation and Experimental Results}

Practical implementation issues of the AT-NPC inverters using advanced WBG power semiconductor devices have got attentions in recent years [22] [23]. There still left many design and implementation issues for the integrated design and control of the AT-NPC inverters with innovative power semiconductor devices and advanced SOPC control technologies. This paper presents the design and implementation of a $3 \mathrm{~kW}$ three-phase 3-L AT-NPC inverter using the GaN HEMT power semiconductor devices from Transform. Table 1 gives some key parameters of the designed inverter.

An FPGA-based predictive control scheme has been developed for the current control and efficiency optimization of the designed three-phase T-type NPC grid-tied inverter. T-type inverter has the features of low conduction losses, low switching losses and superior output waveform quality. These benefits will become significant as the switching frequency decreases. The proposed control scheme is very promising for high power applications. The 3LT2C basically combines the advantages of the 2-level converter such as low conduction losses and small part count with the advantages of the 3-level converter such as low switching losses and superior output voltage quality.

We adopt a modular design method for the design and implementation of the AT-NPC inverter. The converter is designed with a half-bridge AT-NPC inverter as a basic power module. A basic power module includes its own input and output filter, gate drive circuits, protection circuits, sensing and control interface circuits, and a local FPGA-based current controller. Other converters can be constructed with several basic AT-NPC modules. Figure 2 shows the modularized grid converter design methodology.

Table 1. Parameters of the constructed 3L AT-NPC inverter.

\begin{tabular}{ccc}
\hline Parameters & Symbols & Values \\
\hline Nominal output power & $P_{n}$ & $5 \mathrm{~kW}$ \\
Grid voltage & $V_{g}$ & $220 \mathrm{VAC}$ \\
DC-link voltage & $V_{d c}$ & $5380 \mathrm{VDC}$ \\
DC-link capacitance & $C_{d c}$ & $2 \times 470 \mu \mathrm{F}$ in parallel \\
Switching frequency & $F_{s}$ & $48 \mathrm{kHz}$ \\
Inverter-side inductance & $L_{1}$ & $1.2 \mathrm{mH}$ \\
Grid-side inductance & $L_{2}$ & $0.4 \mathrm{mH}$ \\
Output filter capacitance & $C_{f}$ & $22 \mu \mathrm{F}$ \\
\hline
\end{tabular}



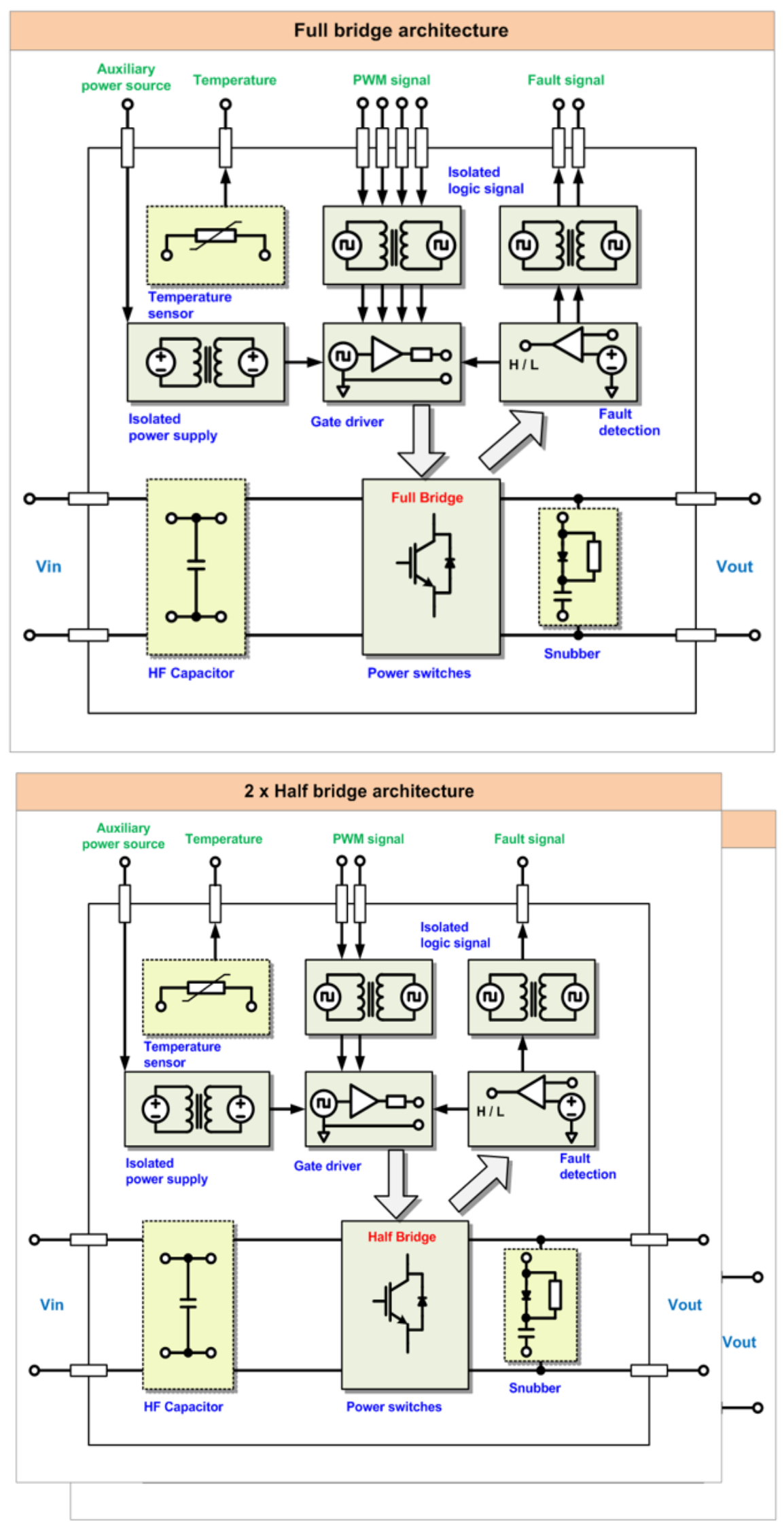

Figure 2. Modularized grid converter design methodology. 
Loss model based on a defined switching waveforms and device characteristics can be used for the efficiency analysis of inverters [24] [25] [26]. The inverter is designed to be operated with a wide range of adjustable switching frequencies from $3 \mathrm{kHz}$ to $60 \mathrm{kHz}$. Figure 3 shows the experimental results of measured output current of the designed 3 L AT-NPC inverter at different loading conditions. Figure 4 shows the measured efficiency and loss distribution as functions of load. A maximum efficiency of 98.49 has been achieved within a load range from $50 \%$ to $75 \%$.

\section{$\mathrm{CH} 1$ : Phase A Voltage $\quad \mathrm{CH} 2$ : Phase A Current}

Pout $=891 \mathrm{~W}(25.5 \%$ Load $)$

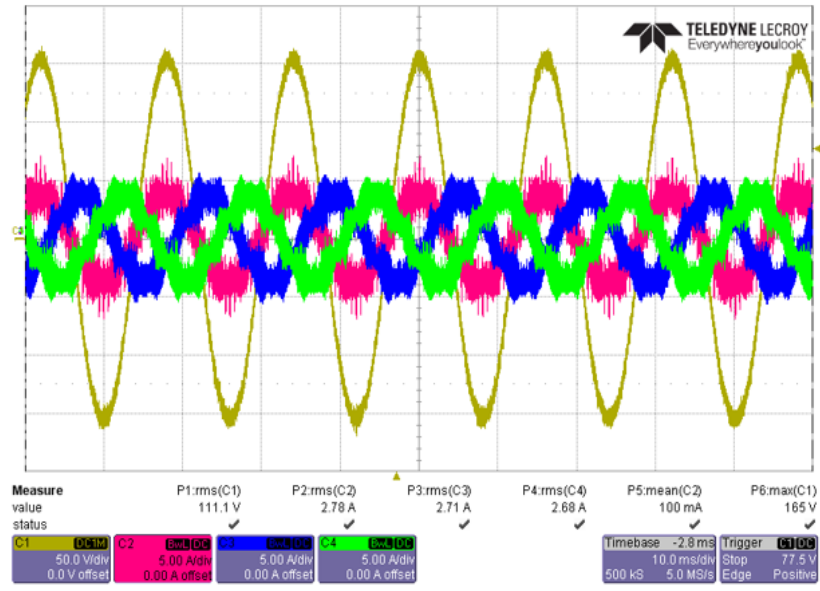

(a)
$\mathrm{CH} 3$ : Phase B Current $\quad \mathrm{CH} 4$ : Phase $\mathrm{C}$ Current

Pout $=3448 \mathrm{~W}(99.7 \%$ Load $)$

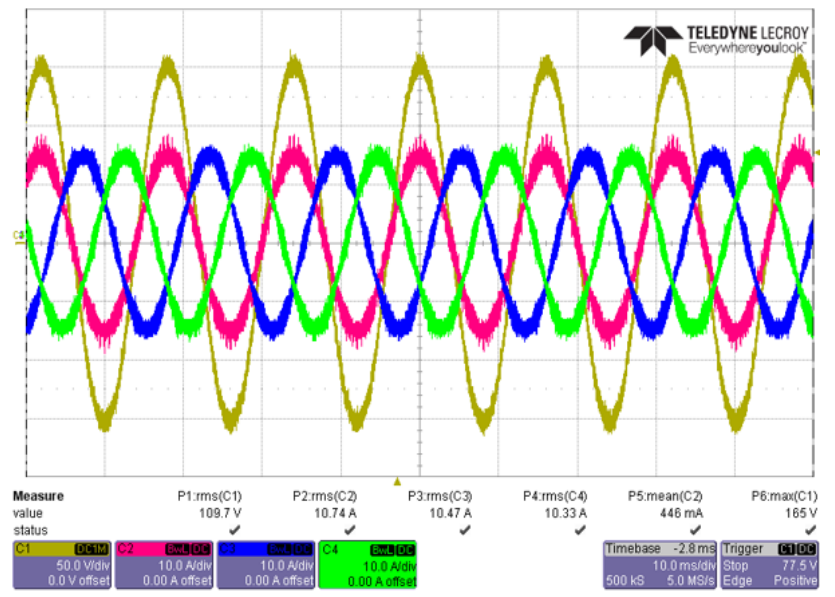

(b)

Figure 3. Measured output current at different load conditions.

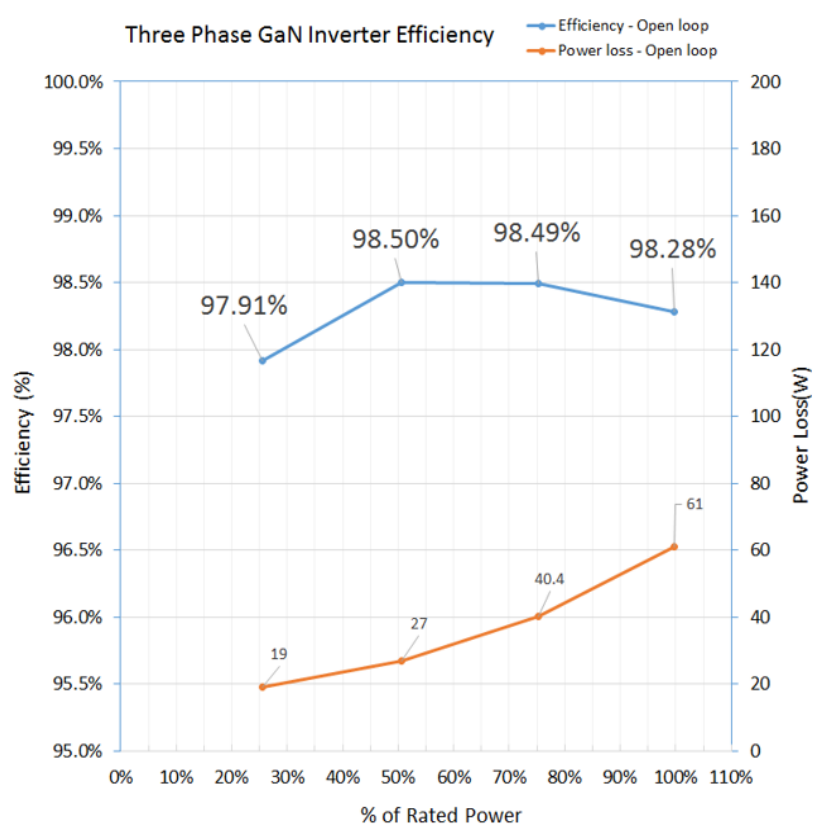

(a)

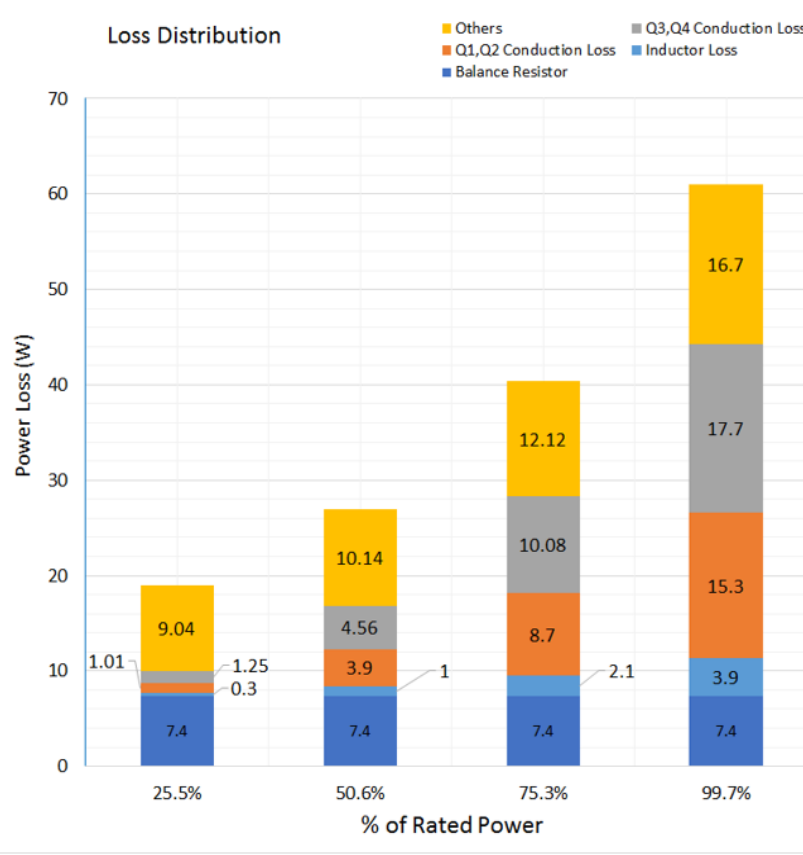

(b)

Figure 4. Measured efficiency and loss distribution. 
Efficiency optimization with adjustable switching frequency and adjustable DC-link voltage can be carried out with a programmable FPGA-based inverter controller. The designed inverter is tested with a nominal switching frequency of $48 \mathrm{kHz}$. Efficiency performance measures are functions of load current, switching frequency, and dc-link voltage. For the selected power devices, conduction loss plays a dominant role for ratings above $70 \%$. Experimental results suggest that an efficiency optimization strategy is required to reduce the conduction losses above a specific load ratio while to reduce the switching losses when the load is lower than this specific load ratio.

\section{Conclusion}

This paper has presented the design and implementation of a $3 \mathrm{kVA}$ three-phase active T-type neutral-point clamped (NPC) inverter with GaN HEMT power devices for low-voltage microgrids. For the selected power devices, conduction loss plays a dominant role for ratings above 70\%. Experimental results suggest that an efficiency optimization strategy is required to reduce the conduction losses above a specific load ratio while to reduce the switching losses when the load is lower than this specific load ratio. A maximum efficiency of $98.49 \%$ has been achieved within a load range from $50 \%$ to $75 \%$.

\section{References}

[1] Nabae, A., Takahashi, I. and Akagi, H. (1981) A New Neutral-Point-Clamped PWM Inverter. IEEE Trans. Ind. Appl., 17, 518-523. https://doi.org/10.1109/TIA.1981.4503992

[2] Franquelo, L.G., Rodriguez, J., Leon, J.I., Kouro, S., Portillo, R. and Prats, M.A.M. (2008) The Age of Multilevel Converters Arrives. IEEE Ind. Electron. Mag., 2, 28-39. https://doi.org/10.1109/MIE.2008.923519

[3] Rodriguez, J., Bernet, S., Wu, B., Pontt, J.O. and Kouro, S. (2007) Multi-Level Voltage-Source-Converter Topologies for Industrial Medium-Voltage Drives. IEEE Trans. Ind. Electron., 54, 2930-2945.https://doi.org/10.1109/TIE.2007.907044

[4] Rodriguez, J., Bernet, S., Steimer, P.K. and Lizama, I.E. (2010) A Survey on NeutralPoint-Clamped Inverters. IEEE Trans. Ind. Electron., 57, 2219-2230. https://doi.org/10.1109/TIE.2009.2032430

[5] Koutroulis, E. and Blaabjerg, F. (2013) Design Optimization of Transformerless Grid-Connected Pv Inverters Including Reliability. IEEE Trans. on Power Electronics, 28, 325-335.https://doi.org/10.1109/TPEL.2012.2198670

[6] Schweizer, M., Friendly, T. and Kolar, J.W. (2013) Comparative Evaluation of Advanced Three-Phase Three-Level Inverter/Converter Topologies against Two-Level Systems. IEEE Trans. Ind. Electron., 60, 5515-5527. https://doi.org/10.1109/TIE.2012.2233698

[7] Teichmann, R. and Bernet, S. (2005) A Comparison of Three-Level Converters versus Two-Level Converters for Low-Voltage Drives, Traction, and Utility Applications. IEEE Trans. on Industry Applications, 41, 855-865. https://doi.org/10.1109/TIA.2005.847285

[8] Minghui, Z. and Komatsu, K. (2012) Three-Phase Advanced Neutral-Point-Clamped Igbt Module with Reverse Blocking IGBTs. International Power Electronics and Mo- 
tion Control Conference (IPEMC), 229-232.

https://doi.org/10.1109/IPEMC.2012.6258835

[9] Maximilian, S., Benjamin, S. and Uwe, J. (2016) Evaluation of a NPC1 Phase Leg Built from Three Standard IGBT Modules for 1500 VDC Photovoltaic Central Inverters Up to $800 \mathrm{Kva}$. 18th European Conference on Power Electronics and Applications (EPE16 ECCE Europe), 1-8.

[10] Mario, S. and Johann, W.K. (2013) Design and Implementation of a Highly Efficient Three-Level T-Type Converter for Low-Voltage Applications. IEEE Trans. on Power Electronics, 28, 899-907. https://doi.org/10.1109/TPEL.2012.2203151

[11] Mario, S. and Johann, W.K. (2011) High Efficiency Drive System with 3-Level TType Inverter. 14th European Conference on Power Electronics and Applications (EPE Conf. Proc.), 1-10.

[12] Morita,T., Tamura, S., Anda, Y., Ishida, M., Uemoto, Y., Ueda, T., Tanaka, T. and Ueda, D. (2011) 99.3\% Efficiency of Three-Phase Inverter for Motor Drive Using Gan-Based Gate Injection Transistors. IEEE APEC Conf. Proc., 481-484. https://doi.org/10.1109/apec.2011.5744640

[13] Mecke, R. (2015) Energy Efficiency of Two-Level and Multilevel Inverters-A Drive System Comparison. 17 th European Conference on Power Electronics and Applications (EPE ECCE-Europe), Geneva, 1-8. https://doi.org/10.1109/EPE.2015.7309068

[14] Xuan, Y., Tian, M.F., Song, X.M., Chen, W.J. and Yang, X. (2015) Design and Implementation of a High Power Three-Level T-Type Inverter for A Photovoltaic System. 9th International Conference on Power Electronics and ECCE Asia (ICPEECCE Asia), 2808-2813.

[15] Ramkrishan, M., Stig, M.-N. and Sergio, B.-M. (2013) Design of Neutral-Point Voltage Controller of a Three-Level NPC Inverter with Small DC-link Capacitors. IEEE Trans. on Industry Electronics, 60, 1861-1871. https://doi.org/10.1109/TIE.2012.2202352

[16] Transphorm. (2014) GaN Power Low-Loss Switch, TPH3006LS Datasheet. http://www.transphormusa.com/

[17] GaN Systems. (2015) 650V Enhanced Mode GaN Transistor, GS66508 Datasheet. http://www.gansystems.com/

[18] Cree. (2014) Silicon Carbide Power MOSFET, C3M0064090J Datasheet. http://www.wolfspeed.com/

[19] Liu, Z., Huang, X., Zhang, W., Lee, F. C. and Li, Q. (2014) Evaluation of High Voltage CascodeGaN HEMT in Different Packages. Proceedings of IEEE Appl. Power Electron. Conf. Expo. (APEC), 168-173. https://doi.org/10.1109/APEC.2014.6803305

[20] Jones, E.A., Wang, Fred, Costinett, Daniel, Zhang, Z.Y., Guo, B., Liu, B. and Ren, R. (2015) Characterization of an Enhancement-Mode 650-V GaN HFET. Proceedings of IEEE Energy Convers. Congr. Expo. (ECCE), 400-407.

[21] Joshin, K., Kikkawa, T., Masuda, S. and Watanabe, K. (2014) Outlook for GaN HEMT Technology. FUIITSU Sci. Tech. J., 50, 138-143.

[22] Wang, Z., Honea, J. and Wu, Y. (2015) Design and Implementation of a High-Efficiency Three-Level Inverter UsingGaN HEMTs. Proceedings of PCIM Europe, International Exhibition and Conference for Power Electronics, Intelligent Motion, Renewable Energy and Energy Management, Nuremberg, 1-7.

[23] Gurpinar, E. and Castellazzi, A. (2016) Single-Phase T-Type Inverter Performance Benchmark Using Si IGBTs, SiC MOSFETs, and GaN HEMTs. IEEE Transactions on Power Electronics, 31, 7148-7160.

[24] Wu, W.M., Wang, X.L., Geng, P. and Tang, T.H. (2008) Efficiency Analysis for Three 
Phase Grid-Tied PV Inverter. IEEE International Conference on Industrial Technology, Chengdu, 1-5.

[25] Zhou, H., Hu, B., Qu, K.W., Liu, Y. and Tong, C.N. (2012) The Efficiency Analysis for Three-Level Grid Connected Photovoltaic Inverters. IEEE International Symposium on Industrial Electronics, 1086-1090.

[26] Lee, K., Shin, H. and Choi, J. (2015) Comparative Analysis of Power Losses for 3-Level NPC and T-Type Inverter Modules. IEEE International Telecommunications Energy Conference (Intelec), Osaka, 1-6.

Submit or recommend next manuscript to SCIRP and we will provide best service for you:

Accepting pre-submission inquiries through Email, Facebook, LinkedIn, Twitter, etc. A wide selection of journals (inclusive of 9 subjects, more than 200 journals)

Providing 24-hour high-quality service

User-friendly online submission system

Fair and swift peer-review system

Efficient typesetting and proofreading procedure

Display of the result of downloads and visits, as well as the number of cited articles Maximum dissemination of your research work

Submit your manuscript at: http://papersubmission.scirp.org/

Or contact epe@scirp.org 